\title{
Upper gastrointestinal bleeding after open heart surgery
}

\author{
Aithoussa Mahdi, Atmani Noureddine, Moutakiallah Younes, Bamous Mehdi, Abdou Abdessamad, \\ Nya Fouad, Seghrouchni Aniss, Wahid Fouad Amal, Drissi Mohamed ${ }^{1}$, Hatim Ghadbane Abdedaim¹, \\ El Bekkali Youssef, Boulahya Abdelatif
}

Departments of Cardiac Surgery and ${ }^{1}$ Reanimation of Cardiac Surgery, Mohammed V Military Hospital, Rabat, Morocco

\begin{abstract}
Objective: The occurrence of digestive complications especially upper gastrointestinal bleeding (UGIB) has increased after cardiac surgery. The aim of this study was to determine the incidence of UGIB and identify the independent risk factors. Materials and Methods: We retrospectively analyzed data of 1077 patients undergoing cardiopulmonary bypass (CPB) from 1994 to 2012 The group of patients with UGIB $\left(n_{1}=20\right)$ was compared with the population group $\left(n_{2}=1057\right)$. Demographic characteristics, therapeutic management, endoscopic findings, and outcomes were analyzed. Through a regression analysis we identified independent risk factors of UGIB. Results: The mean age of the group $n_{1}$ was $58.2 \pm 12.4$ years and $50.18 \pm 13.5$ years in the group $n_{2}$. UGIB occurred about $13 \pm 5.5$ days after cardiac surgery. Gastroduodenal ulcer was the most common etiology of hemorrhage $(n=13,65 \%)$. Renal insufficiency, previous gastric ulcer, increased lactate concentration during CPB, prolonged mechanical ventilation, use of vasopressor drug and pulmonary infection was likely contributing factors in UGIB. Conclusion: UGIB following open cardiac surgery is most frequently secondary to gastroduodenal ulceration. Many determinant factors of bleeding are incriminated. Surgeons must be aware of these factors to avoid fatal complications.
\end{abstract}

Key words Gastrointestinal bleeding, open cardiac surgery, postoperative complications, stress ulceration

\section{Introduction}

Cardiac surgery using cardiopulmonary bypass $(\mathrm{CPB})$ is a common major surgical procedure that imposes considerable physiological multi-organ stress despite the recent technological advances. ${ }^{[1]}$ Peptic ulcer disease (PUD) and bleeding from the upper gastrointestinal (GI) tract is a rare serious postoperative complication $(0.35-0.9 \%)$ with significant morbidity. ${ }^{[2-4]}$ Blood transfusion, endoscopic or surgical treatment are always required, with an increased hospital costs. ${ }^{[5]}$ Many factors were identified as predictive of GI bleeding (GIB). It is, therefore,

\begin{tabular}{|l|c|}
\hline \multicolumn{2}{|c|}{ Access this article online } \\
\hline \multirow{2}{*}{$\begin{array}{l}\text { Website: } \\
\text { www.jdeonline.in }\end{array}$} & Quick Response Code \\
\hline DOI: & \\
10.4103/0976-5042.147501 & \\
\hline
\end{tabular}

important to prevent these factors and this complication since fatal complications are noted in $35 \%{ }^{[6]}$

\section{Materials and Methods}

The 1077 patients who underwent open heart surgery were retrospectively evaluated for GIB. All patients presenting with GIB within 30 days following cardiac surgery were included. GIB was defined as hematemesis, melena, nasogastric tube aspiration of blood material, hematochezia on rectal examination, or the combination of guaiac positive stools on occult blood testing and significant decline in the hemoglobin level $(<10 \mathrm{~g} / 1)$ with transfusion of $>2$ units of blood. ${ }^{[7]}$ Were excluded: patients whose GIB was due to bleeding endoscopic varices, patients with lower intestinal bleeding. All patients underwent either coronary artery bypass grafting $(\mathrm{CABG})$, valve surgery combined valve surgery and $C A B G$, thoracic aortic surgery or surgical correction of adult congenital heart defects. Extracorporeal circulation was conducted between ascending aorta and 
right atrial or bicaval cannulation using a roller pump, and membranous oxygenation. Blood temperature was maintained between $32^{\circ} \mathrm{C}$ and $34^{\circ} \mathrm{C}$ range. Before the year 2000 myocardial protection was performed with cold crystalloid intermittent antegrade cardioplegia and antegrade blood cardioplegia since 2000 was daily used. Routine protocol of the cardiovascular surgery department was applied to all patients. Acetyl salicylic acid was not stopped before surgery. All patients received a $40 \mathrm{mg}$ dose of diazepam, and $100 \mathrm{mg}$ of hydroxyzine was administered per os the night before the surgery. Before 2000, patients were received histamine 2 receptor blockers from the first operative day for 1 month. After 2000, all patients received proton pump inhibitors (PPIs) intravenously for 2 days, followed by $20 \mathrm{mg}$ per os for $1 \mathrm{month}$. Preoperative gastroscopy for patients with a history of gastroduodenal ulcer (GDU) or gastritis was systematic. If the previous ulcer is healed and there are no others lesions, the patient underwent cardiac surgery. Unlike, the therapy is based on the inhibition of gastric acid by PPIs and eradication of Helicobacter pylori infection, followed a month after by endoscopic control.

Management of GIB has changed in our institution. Since 2000 , endoscopic therapy is generally recommended as the first-line treatment. Medical therapy included after stopping anticoagulation, red blood transfusion and intravenous PPIs until the bleeding control. The demographic, operative and postoperative findings of the patients were recorded.

Statistical analysis was performed with SPSS software version 19.0 (SPSS Inc., Chicago, IL, USA). Continuous variables were expressed as mean \pm standard deviation, or median and categorical variable as proportions. Logistic regression with step-wise back and elimination was performed to identify possible predictor factors with the upper GIB (UGIB).

\section{Results}

A total of 1077 adult patients who underwent CPB were included in this study. GIB occurred in 1.83\% (20/1077).

\section{Patient characteristics}

Patients with and without GIB were similar when compared for age, smoking, vascular disease, left ventricular function, Canadian Cardiovascular Society angina class, functional class New York Heart Association (NYHA) III-IV [Table 1]. We found significant differences between the groups in male-female ratio, renal dysfunction, peripheral arterial disease, and prior cardiac surgery. GIB was more common in the patients who had a history of PUD and/or gastritis ( $4 \%$ vs. $20 \%, P<0.0001)$. On the other hand, no significant differences were observed between the groups in terms of operative parameters (emergency surgery, CPB time, aortic cross-clamp time, and type of surgery). However regarding postoperative parameters, mechanical ventilation and ICU stay were longer

\begin{tabular}{lccc}
\hline \multicolumn{4}{l}{ Table 1: Clinical characteristic of cases and controls } \\
\hline Variable & $\begin{array}{c}\text { Controls } \\
(n=1057)(\%)\end{array}$ & $\begin{array}{c}\text { Cases } \\
(n=20)(\%)\end{array}$ & $P$ \\
\hline Age (years) & $50.18 \pm 13.5$ & $58.2 \pm 12.4$ & 0.42 \\
Sex: Male/female & $718 / 355$ & $18 / 2$ & 0.027 \\
BMI (kg/m²) & $24.8 \pm 5.4$ & $25.3 \pm 2.9$ & 0.3 \\
Smoking & $455(41.9)$ & $12(60)$ & 0.1 \\
Diabetes mellitus & $261(24.6)$ & $7(35)$ & 0.28 \\
Hypertension & $235(22.1)$ & $8(40)$ & 0.09 \\
Chronic obstructive pulmonary & $102(9.6)$ & $1(5)$ & 0.48 \\
Renal insufficiency & $84(7.9)$ & $5(25)$ & 0.006 \\
Cerebro-vascular disease & $37(3.5)$ & 0 & 0.39 \\
Peripheral vascular disease & $124(11.7)$ & $4(20)$ & 0.047 \\
History of peptic ulcer disease & $42(4)$ & $4(20)$ & 0.000 \\
and/or gastritis & & & \\
CCS angine Class III-IV & $155(15.2)$ & $10(50)$ & 0.23 \\
Functional class NYHA II-IV & $447(42.7)$ & $6(30)$ & 0.3 \\
EF (\%) & $53.3 \pm 14$ & $57.2 \pm 12$ & 0.39 \\
Pulmonary arterial & $48.9 \pm 20$ & $53.8 \pm 26.7$ & 0.45 \\
hypertension mmHg & & & \\
Prior cardiac surgery & $192(18.6)$ & 0 & 0.033 \\
Atrial fibrillation & $273(25)$ & $3(15)$ & 0.53 \\
Mean Euroscore & $3.97 \pm 3.2$ & $3.8 \pm 3.9$ & 0.1 \\
\hline
\end{tabular}

$\mathrm{BMl}=$ Body mass index, CCS=Canadian cardiovascular society, NYHA=New York heart association, $E F=E j e c t i o n$ fraction

in the GIB group. No significant differences were found between the groups when we compare low cardiac output, use of intra-aortic balloon pump (IABP), and postoperative myocardial infarction. Patients developing renal insufficiency with/or without requiring hemodialysis were significantly more likely to experience GI hemorrhage $(P<0.0001)$. Similarly, patients requiring pharmacological support with vasopressor drug and those who developed pulmonary infection were also more likely to experience a GIB. Acute cerebral stroke, multi-organ failure (MOF), and need for chest reexploration were frequent in GIB group. Mean lactate concentration during CPB was higher in GIB group $(P<0.0001)$. Hospital mortality increased more in patients with UGIB $(7.3 \%$ vs. $25 \%, P=0.0013)$. To identify associated factors to UGIB after $\mathrm{CPB}$, logistic regression with step-wise back and elimination was performed [Table 2]. We found seven possible predictor factors of UGIB: Renal insufficiency, previous GDU, increased lactate concentration per $\mathrm{CPB}$, need of vasopressor drug, prolonged mechanical ventilation, pulmonary infection, and MOF. The mean interval between cardiac surgery and onset of GI hemorrhage was $13 \pm 5.5$ days (range 4-25 days). Symptoms were hematemesis $(n=4)$, melena $(n=9)$, hematemesis-melena $(n=7)$. Five patients had recurrent bleeding [Table 3]. Eighteen patients underwent endoscopic examination. Two patients did not undergo endoscopy because they were hemodynamically unstable. The following endoscopic diagnoses were confirmed: duodenal ulcer $(n=6)$, gastric ulcer $(n=4)$, gastric + duodenal ulcer $(n=3)$, ulcerohemorrhagic oesophagitis $(n=2)$ and erosive gastritis $(n=3)$. Bleeding control required surgery in 2 cases, therapeutic endoscopy in 6 patients and medical therapy in 12 patients. 


\begin{tabular}{|c|c|c|c|}
\hline Variable & $\begin{array}{c}\text { Controls } \\
(n=1057) \\
(\%)\end{array}$ & $\begin{array}{c}\text { Cases } \\
(n=20)(\%)\end{array}$ & $P$ \\
\hline \multicolumn{4}{|l|}{ Operative data } \\
\hline Emergency surgery & $70(6.6)$ & $1(5)$ & 0.77 \\
\hline CPB time (min) & $104.8 \pm 44$ & $101.2 \pm 28.2$ & 0.08 \\
\hline Aortic cross clamp time (min) & $67.6 \pm 32.8$ & $59 \pm 19.1$ & 0.06 \\
\hline Operative time (min) & $216.5 \pm 63.7$ & $226.7 \pm 73.1$ & 0.5 \\
\hline Mechanical ventilation time $(h)$ & $9(6-18)$ & $17(9-28)$ & 0.023 \\
\hline Mechanical ventilation up to $48 \mathrm{~h}$ & $86(8.3)$ & $7(35)$ & 0.008 \\
\hline ICU length of stay (h) & $48(24-64)$ & $72(41-174)$ & 0.008 \\
\hline Hospital stay (days) & $13.7 \pm 14$ & $19.4 \pm 10.4$ & 0.008 \\
\hline \multicolumn{4}{|l|}{ Postoperative complications } \\
\hline Low cardiac output & $148(14.1)$ & $(5.25)$ & 0.18 \\
\hline \multicolumn{4}{|l|}{ Need for vasopressor drug } \\
\hline Inotropics $>0.02 \mu \mathrm{g} / \mathrm{kg}$ epinephrine & $204(19.4)$ & $8(40)$ & 0.022 \\
\hline IABP & $83(7.9)$ & $2(10)$ & 0.98 \\
\hline Chest reexploration for bleeding & $51(4.9)$ & $3(15)$ & 0.041 \\
\hline Pulmonary infection & $89(8.5)$ & $6(30)$ & 0.001 \\
\hline Acute renal failure & $99(9.5)$ & $6(30)$ & 0.002 \\
\hline Need for dialysis & $23(2.2)$ & $3(15)$ & 0.000 \\
\hline Acute cerebrovascular accident & $17(1.7)$ & $2(10)$ & 0.006 \\
\hline Transfusion & $424(41.2)$ & $18(90)$ & 0.000 \\
\hline In-hospital mortality & $77(7.3)$ & $5(25)$ & 0.013 \\
\hline Arythmia & $63(6)$ & $3(15)$ & 0.098 \\
\hline Postoperative myocardial infarction & $23(2.2)$ & $1(5)$ & 0.73 \\
\hline Lactate & $2.3 \pm 1.3$ & $5.5 \pm 6.3$ & 0.000 \\
\hline MOF & $52(5.1)$ & $5(25)$ & 0.000 \\
\hline
\end{tabular}

pump, $\mathrm{CPB}=$ Cardiopulmonary bypass

\section{Discussion}

The large use of cardiac surgery has increased the occurrence of digestive complications, especially upper digestive tract bleeding. In this retrospective study, UGIB following open heart surgery showed an overall incidence of $1.85 \%$ and was associated with a high mortality of $25 \%$ in comparison with literature ${ }^{[8,9]}$ Bleed from upper GI tract was the most common noted complication. ${ }^{[5,10-13]}$ van der Voort and Zandstra $^{[2]}$ reviewed the available publishing literature before 2000 , concerning the incidence of upper GIB and found it occurring in $0.45-2 \%$. The same result was reported by Aljarallah et al. ${ }^{[14]}$ In numerous published papers, we noted UGIB rate did not decline through the years despite constant improvements in medical management. In general, upper GIB occurs more frequently than lower intestinal bleeding. The site of the bleed is proximal to the ligament of Treitz in more than $90 \%{ }^{[15]}$ The two most common etiologies of upper GIB are GI ulceration and gastric erosion..$^{[3,8,16-18]}$ In our study, GI ulceration was responsible for bleeding in 13 cases $(65 \%)$, and erosive gastritis in 3 cases (15\%). Our results confirmed the literature data and GIB occurred around 10 days after surgery. $[8,9,16,18,19]$

Delayed diagnosis is frequent because of undiagnosed symptoms particularly in sedated patients. In the absence of hematemesis, a particular attention should be accorded to the nasogastric tube contents. Gastric endoscopy is the next step in evaluation and treatment of potential digestive bleeding. ${ }^{[20]}$ The pathogenesis of mucosal damage and subsequent bleeding is complex and multifactorial including psychological and physiological stress and postoperative complications. ${ }^{[16]}$ Upper GI hemorrhage due to stress ulceration is the most commonly identified mechanism. ${ }^{[2]]}$ According to Bhat et al. ${ }^{[8]}$ and Amorin et al. ${ }^{[9]} 85.5 \%$ of patients had ulcers on endoscopy. Stress ulceration has been attributed to ischemia and/or reperfusion injury of the splanchnic territory and endotoxemia leading to gastroduodenal mucosa damage. ${ }^{[21,22]}$ Rey et al. ${ }^{[23]}$ have observed some special characteristics in case of bleeding ulceration: first, digestive bleeding is frequent in patients who underwent cardiac surgery for coronary artery bypass grafting than in the case of heart valve replacement. Second, in the case of earlier hemorrhage after surgery ( 1 after 5 days), endoscopic examination showed multiple superficial gastric and duodenal ulcerations. In Yoshida et al. study, ${ }^{[18]}$ the onset of UGIB was $13.1 \pm 9.3$ days and no cases of single peptic ulcer were observed. In our study, gastroscopy found gastric and duodenal ulcer in 13 cases $(65 \%)$. Third, a second bleeding period occurred during the $3^{\text {rd }}$ week following surgery, and they have usually observed in endoscopy a large duodenal bleeding ulcer. There are controversial opinions about the role of preexisting PUD as a cause of postoperative hemorrhage. In some reports, patients with a history of PUD were more exposed to have UGIB. ${ }^{[24,25]}$ In other reports, there is no significant evidence that a previous history of PUD would be correlated with increased risk for gastric hemorrhage. ${ }^{[26]}$ In a study published by Geissler et al., ${ }^{[27]}$ among 41 patients with UGIB, only 2 cases had a history of gastritis or peptic ulcer. In our study, four patients (20\%) had a history of GDU disease, and in logistic regression analysis, it predicted UGIB (odds ratio: 6, confidence interval $95 \%, 1.9-18.8 ; P=0.002$ ) [Table 4]. CPB is known to cause increased systemic inflammation and therefore many have suggested that performing coronary bypass grafting off-pump could substantially minimize the risk of digestive complications. According to the Raja et al. ${ }^{[28]}$ finding, CPB is the main independent predictor of postoperative GI complications; the risk being seven times higher in the on-pump compared with the off-pump group (Raja et al.). In recent prospective randomized study, Croome et al. did not find any statistically significant difference in the total number of GI complications between the off-pump and on-pump groups. ${ }^{[29]}$ Several studies have examined pharmacological stress prophylaxis in patients undergoing cardiac surgery. The benefit of histamine 2 receptor antagonists (H2RA) to protect the stomach is still discussed. Many investigators demonstrated that H2RA were effective in decreasing surgical stress response and preventing clinical GIB. ${ }^{[30-32]}$ In a recent meta-analysis, prophylactic PPIs could reduce hemorrhagic gastritis and hematemesis but was associated with an increased risk of nosocomial pneumonia. ${ }^{[33]}$ Therefore, PPI are considered mandatory to prevent the upper GIB after open heart procedure ${ }^{[30]}$ particularly in patients with an increased risk of GIB after cardiac surgery. According to the literature, intra-operative factors, such as $\mathrm{CPB}$ time and 


\begin{tabular}{lc}
\hline Table 3: Diagnosis and treatment in patients developing UGIB \\
\hline Variable & Patients $(\boldsymbol{n}=\mathbf{2 0})$ \\
\hline Symptoms & 04 \\
Hematemesis & 09 \\
Maelena & 07 \\
Hematemesis and maelena & 05 \\
Recurrent GIB & \\
Endoscopic fundings & 06 \\
Duodenal ulcer & 04 \\
Gastric ulcer & 03 \\
Gastric and duodenal ulcer & 03 \\
Erosive gastritis & 02 \\
Erosive esophagitis & 02 \\
Unknown & \\
Treatment & 12 \\
Medical therapy & 06 \\
Endoscopic therapy & 02 \\
Surgery & $13 \pm 5.5$ \\
Onset of UGIB (days)
\end{tabular}

UGIB=Upper gastrointestinal bleeding, GIB=Gastrointestinal bleeding

\begin{tabular}{lccc}
\hline \multicolumn{4}{l}{ Table 4: Multivariate predictors of UGIB after cardiac surgery } \\
\hline Variable & OR & $95 \%, \mathrm{CI}$ & $\boldsymbol{P}$ \\
\hline Renal insufficiency & 3.8 & $1.3,10.8$ & 0.011 \\
Previous gastroduodenal ulcer & 6 & $1.9,18.8$ & 0.002 \\
Mean lactate concentration per CPB & 1.4 & $1.1,1.9$ & 0.002 \\
Use of vasopressor drug & 2.7 & $1.1,6.8$ & 0.028 \\
Prolonged mechanical ventilation & 5.9 & $2.3,15.3$ & 0.000 \\
Pulmonary infection & 4.6 & $1.7,12.3$ & 0.002 \\
Postoperative renal insuffisancy & 4.1 & $1.5,10.9$ & 0.005 \\
Need for hemodialysis & 7.8 & $2.1,28.6$ & 0.002 \\
MOF & 6.2 & $2.1,17.8$ & 0.001 \\
\hline UGIB=Upper gastrointestinal bleeding, Cl=Confidence interval, OR=Odds \\
ratio, CPB=Cardiopulmonary bypass, MOF=Multi-organ failure
\end{tabular}

some postoperative events, such as low output syndrome, necessity of surgery, use of IABP and the development of acute renal failure are good indicators of low output. The relationship between prolonged mechanical ventilation with high positive end-expiratory pressure has been documented in various studies. ${ }^{[3,35]}$ In our study, we concluded a higher incidence of UGIB in patients with renal insufficiency, prolonged mechanical ventilation, pulmonary infection and MOF. Previous PUD, increased lactate per CPB or hemodynamic instability requiring vasopressor may also be a determinant for potential upper gastric haemorrhage. On the other hand, some risk factors of UGIB, such advanced age, NYHA functional Class IV, smoking, diabetes mellitus, left ventricular dysfunction, emergent surgery, blood transfusion are incriminated. ${ }^{[10,34,36,37]}$ The first case of UGIB reported in the literature required subtotal or total gastrectomy with a high mortality rate ranging from $20 \%$ to $40 \% .{ }^{[16,38]}$ Nowadays initial treatment consists on rapid correction of coagulation disorders, red blood transfusion followed by endoscopy. Endoscopic treatment achieves control in $98 \%$ of patients and many authors consider it a treatment of choice in high risk patients. ${ }^{[16,39,40]}$ In our study, endoscopic procedures were successfully practiced by experienced interventional endoscopists. Surgery was performed only in 2 cases, 1 in 1994 and other 1 in because of recurrent massive GIB.

\section{Conclusion}

Upper GIB is the most clinical problem after open cardiac surgery. Many risk factors were identified. This condition should increase the awareness of physicians to identify susceptible patients, to contribute to early diagnosis, and to prevent fatal consequences.

\section{References}

1. Suleiman MS, Zacharowski K, Angelini GD. Inflammatory response and cardioprotection during open-heart surgery: The importance of anaesthetics. Br J Pharmacol 2008;153:21-33.

2. van der Voort PH, Zandstra DF. Pathogenesis, risk factors, and incidence of upper gastrointestinal bleeding after cardiac surgery: Is specific prophylaxis in routine bypass procedures needed? J Cardiothorac Vasc Anesth 2000;14:293-9.

3. Egleston CV, Wood AE, Gorey TF, McGovern EM. Gastrointestinal complications after cardiac surgery. Ann R Coll Surg Engl 1993;75:52-6.

4. Andersson B, Nilsson J, Brandt J, Höglund P, Andersson R. Gastrointestinal complications after cardiac surgery. Br J Surg 2005;92:326-33.

5. D’Ancona G, Baillot R, Poirier B, Dagenais F, de Ibarra JI, Bauset R, et al. Determinants of gastrointestinal complications in cardiac surgery. Tex Heart Inst J 2003;30:280-5.

6. Rockall TA, Logan RF, Devlin HB, Northfield TC. Incidence of and mortality from acute upper gastrointestinal haemorrhage in the United Kingdom. Steering Committee and Members of the National Audit of Acute Upper Gastrointestinal Haemorrhage. BMJ 1995;311:222-6.

7. Barkun A, Sabbah S, Enns R, Armstrong D, Gregor J, Fedorak RN, et al. The Canadian Registry on Nonvariceal Upper Gastrointestinal Bleeding and Endoscopy (RUGBE): Endoscopic hemostasis and proton pump inhibition are associated with improved outcomes in a real-life setting. Am J Gastroenterol 2004;99:1238-46.

8. Bhat M, Larocque M, Amorim M, Herba K, Martel M, De Varennes B, et al. Prediction and prevention of upper gastrointestinal bleeding after cardiac surgery: A case control study. Can J Gastroenterol 2012;26:340-4.

9. Amorim M, Barkun AN, Larocque M, Herba K, De Varennes B, Martel M. In-hospital nonvariceal upper gastrointestinal bleeding following cardiac surgery: Patient characteristics, endoscopic lesions and prognosis. Ulcers 2012;2012:1-5.

10. Bolcal C, Iyem H, Sargin M, Mataraci I, Sahin MA, Temizkan V, et al. Gastrointestinal complications after cardiopulmonary bypass: Sixteen years of experience. Can J Gastroenterol 2005;19:613-7.

11. Filsoufi F, Rahmanian PB, Castillo JG, Scurlock C, Legnani PE, Adams DH. Predictors and outcome of gastrointestinal complications in patients undergoing cardiac surgery. Ann Surg 2007;246:323-9.

12. Khan JH, Lambert AM, Habib JH, Broce M, Emmett MS, Davis EA. Abdominal complications after heart surgery. Ann Thorac Surg 2006;82:1796-801.

13. Aouifi A, Piriou V, Bastien O, Joseph P, Blanc P, Chiari P, et al. Severe digestive complications after cardiac surgery under cardiopulmonary bypass. Can J Anesth 1999;46:114-21.

14. Aljarallah B, Wong W, Modry D, Fedorak R. Prevalence and outcome of upper gastrointestinal bleeding post-coronary artery bypass graft. Int J Health Sci (Qassim) 2008;2:69-76.

15. Yilmaz AT, Arslan M, Demirkilç U, Ozal E, Kuralay E, Bingöl H, et al. Gastrointestinal complications after cardiac surgery. Eur J Cardiothorac Surg 1996;10:763-7.

16. Taylor PC, Loop FD, Hermann RE. Management of acute stress ulcer after cardiac surgery. Ann Surg 1973;178:1-5. 
17. Zacharias A, Schwann TA, Parenteau GL, Riordan CJ, Durham SJ, Engoren $\mathrm{M}$, et al. Predictors of gastrointestinal complications in cardiac surgery. Tex Heart Inst J 2000;27:93-9.

18. Yoshida K, Matsumoto M, Sugita T, Nishizawa J, Matsuyama K, Tokuda Y, et al. Gastrointestinal complications in patients undergoing coronary artery bypass grafting. Ann Thorac Cardiovasc Surg 2005;11:25-8.

19. Yamaguchi T, Muraoka R, Tatsuta N, Hikasa Y, Tobe T, Koie H, et al. Acute stress ulcer after cardiac surgery. Nihon Geka Hokan 1980;49:338-43.

20. Soehendra N, Grimm H, Stenzel M. Injection of nonvariceal bleeding lesions of the upper gastrointestinal tract. Endoscopy 1985;17:129-32.

21. Jayaprakash A, McGrath C, McCullagh E, Smith F, Angelini G, Probert C. Upper gastrointestinal haemorrhage following cardiac surgery: A comparative study with vascular surgery patients from a single centre. Eur J Gastroenterol Hepatol 2004;16:191-4.

22. Christenson JT, Schmuziger M, Maurice J, Simonet F, Velebit V. Postoperative visceral hypotension the common cause for gastrointestinal complications after cardiac surgery. Thorac Cardiovasc Surg 1994;42:152-7.

23. Rey JF, Monnot F, Lombart J, Sabatier M, Schmitt R, Arnulf JJ, et al. Endoscopic diagnosis and treatment of acute digestive bleeding in a cardiac surgical department. Acta Endoscopia 1983;13:109-13.

24. Katz SE, Kornfeld DS, Harris PD, Yeoh CB. Acute gastrointestinal ulceration with open heart surgery and aortic valve disease. Surgeon 1972;72:438-42.

25. Lebovics E, Lee SS, Dworkin BM, Heier SK, Casellas A, Reed G, et al. Upper gastrointestinal bleeding following open heart surgery. Predominant finding of aggressive duodenal ulcer disease. Dig Dis Sci 1991;36:757-60.

26. Della Ratta RK, Corapi MJ, Horowitz BR, Calio AJ. Risk of postoperative upper gastrointestinal tract hemorrhage in patients with active peptic ulcer disease undergoing nonulcer surgery. Arch Intern Med 1993;153:2141-4.

27. Geissler HJ, Fischer UM, Grunert S, Kuhn-Régnier F, Hoelscher A, Schwinger $\mathrm{RH}$, et al. Incidence and outcome of gastrointestinal complications after cardiopulmonary bypass. Interactive Cardiovasc Thorac Surg 2006;5:239-42.

28. Raja SG, Haider Z, Ahmed M. Predictors of gastrointestinal complications after conventional and beating heart coronary surgery. Surg J R Coll Surg Edinb Irel 2003;4:221-8.

29. Croome KP, Kiaii B, Fox S, Quantz M, McKenzie N, Novick RJ. Comparison of gastrointestinal complications in on-pump versus off-pump coronary artery bypass grafting. Can J Surg 2009;52:125-8.
30. Hata M, Shiono M, Sekino H, Furukawa H, Sezai A, Iida $M$, et al. Prospective randomized trial for optimal prophylactic treatment of the upper gastrointestinal complications after open heart surgery. Circ J 2005;69:331-4.

31. Wagner BK, Amory DW, Majcher CM, DiFazio LT, Scott GE, Spotnitz AJ. Effects of intravenous famotidine on gastric acid secretion in patients undergoing cardiac surgery. Ann Pharmacother 1995;29:349-53.

32. Tayama E, Hayashida N, Fukunaga S, Tayama K, Takaseya T, Hiratsuka R, et al. High-dose cimetidine reduces proinflammatory reaction after cardiac surgery with cardiopulmonary bypass. Ann Thorac Surg 2001;72:1945-9.

33. Shin JS, Abah U. Is routine stress ulcer prophylaxis of benefit for patients undergoing cardiac surgery? Interact Cardiovasc Thorac Surg 2012;14:622-8.

34. Spotnitz WD, Sanders RP, Hanks JB, Nolan SP, Tribble CG, Bergin JD, et al. General surgical complications can be predicted after cardiopulmonary bypass. Ann Surg 1995;221:489-96.

35. Simić O, Strathausen S, Hess W, Ostermeyer J. Incidence and prognosis of abdominal complications after cardiopulmonary bypass. Cardiovasc Surg 1999;7:419-24.

36. Recht MH, Smith JM, Woods SE, Engel AM, Hiratzka LF. Predictors and outcomes of gastrointestinal complications in patients undergoing coronary artery bypass graft surgery: A prospective, nested case-control study. J Am Coll Surg 2004;198:742-7.

37. Perugini RA, Orr RK, Porter D, Dumas EM, Maini BS. Gastrointestinal complications following cardiac surgery. An analysis of 1477 cardiac surgery patients. Arch Surg 1997;132:352-7.

38. Cheynel N, Peschaud F, Hagry O, Rat P, Ognois-Ausset P, Favre JP. Bleeding gastroduodenal ulcer: Results of surgical management. Ann Chir 2001;126:232-5.

39. Loffroy R, Guiu B. Role of transcatheter arterial embolization for massive bleeding from gastroduodenal ulcers. World J Gastroenterol 2009;15:5889-97.

40. Krasna MJ, Flancbaum L, Trooskin SZ, Fitzpatrick JC, Scholz PM, Scott GE, et al. Gastrointestinal complications after cardiac surgery. Surgery 1988;104:773-80.

How to cite this article: Mahdi A, Noureddine A, Younes M, Mehdi B, Abdessamad A, Fouad N, et al. Upper gastrointestinal bleeding after open heart surgery. J Dig Endosc 2014;5:101-5.

Source of Support: Nil, Conflict of Interest: None declared. 